\title{
Measuring the economic burden for TB patients in the End TB Strategy and Universal Health Coverage frameworks
}

\author{
D. Pedrazzoli, ${ }^{*}$ J. Borghi, ${ }^{\dagger}$ K. Viney, ${ }^{\ddagger}$ R. M. G. J. Houben, ${ }^{*}$ K. Lönnroth ${ }^{\ddagger}$ \\ Departments of ${ }^{*}$ Infectious Disease Epidemiology, ${ }^{\dagger}$ Global Health and Development, London School of Hygiene \& \\ Tropical Medicine, London, UK; ${ }^{\ddagger}$ Department of Public Health Sciences, Karolinska Institutet, Stockholm, Sweden; \\ ${ }^{\S}$ Research School of Population Health, Australian National University, Canberra ACT, Australia
}

SUM M ARY

Tuberculosis $(\mathrm{TB})$ is a disease of poverty. Ensuring access to health care without the risk of financial hardship due to out-of-pocket health care expenditures (Universal Health Coverage [UHC]) is essential for providing accessible care to underprivileged populations, but this is not enough. The End TB Strategy promotes both patient-centred TB services and social protection measures, which aim to mitigate the economic hardship faced by TB patients and their households due to direct medical and non-medical expenditures, as well as to lost income. The strategy includes a target that no families should face catastrophic total costs due to TB. The indicator linked to this target aims to capture the total economic burden linked to TB care, and thus differs from the 'catastrophic expenditure on health' indicator, a key component of the
UHC monitoring framework aligned with the Sustainable Development Goals. Countries, and particularly high TB burden countries, are expected to conduct nationally representative $\mathrm{TB}$ patient cost surveys to establish baseline measurements for the catastrophic costs indicator. Findings from these surveys should also help identify entry points for developing policies to ensure better financial and social protection for TB patients. In this paper, we define the key measurable concepts for TB patient cost surveys, notably the types of costs that are captured, and related affordability measures. We discuss methods for measuring these notions in the UHC framework and contrast them with how they are measured in TB patient cost surveys. KEY WORDS: TB; patient costs; financial protection; affordability
TUBERCULOSIS (TB) REMAINS a major threat to global public health. ${ }^{1}$ Poor people in resourceconstrained settings are most at risk of the disease and its devastating economic consequences. ${ }^{2}$ In lowand middle-income countries (LMICs), health care financing is heavily reliant on out-of-pocket payments. Despite basic TB care being officially free of charge, usually partly through vertical funding mechanisms, TB patients often struggle to afford TB care, and they incur costs considered to be 'catastrophic'. ${ }^{3-5}$

Universal Health Coverage (UHC), whereby everyone can access the quality health services they need without financial hardship, ${ }^{6}$ has long been on the global TB control agenda. Free diagnosis and treatment have been the cornerstone of global TB control strategies since $1994 .^{7}$ The DOTS strategy emphasises the use of low-cost, cost-effective tools and interventions to enable affordable access to quality $\mathrm{TB}$ care, which has resulted in 53 million lives saved. However, this has been shown to be insufficient in mitigating economic consequences, as non-medical costs and income losses, which account for a large part of the economic burden for households, are not accounted for within the UHC monitoring framework. ${ }^{8-10}$

Aligned with the Sustainable Development Goals, the World Health Organization's (WHO's) End TB Strategy has an increased focus on poverty alleviation strategies and social protection initiatives that cover costs beyond medical expenses, including income security. It also includes as a target that no TBaffected families should suffer from catastrophic total costs due to the disease. ${ }^{10,11}$ To monitor progress towards this target, the WHO Global TB Programme convened a task force of experts in 2015 to develop a field-testing protocol and survey instrument for nationally representative, health facility-based surveys of costs faced by $\mathrm{TB}$ patients and their households ('TB patient cost surveys'), building upon the Tool to Estimate Patients' Costs. ${ }^{12}$ After field testing, the WHO developed a handbook for TB patient cost surveys. ${ }^{11}$ Countries, and particularly high TB burden countries, are expected to adapt and

Correspondence to: Debora Pedrazzoli, Department of Infectious Disease Epidemiology, London School of Hygiene \& Tropical Medicine, Keppel Street, London WC1E 7HT, UK. e-mail: debora.pedrazzoli@lshtm.ac.uk

Article submitted 30 April 2018. Final version accepted 23 August 2018. 
implement these surveys to document the magnitude and main drivers of costs incurred by TB patients (and their households) and the proportion of $\mathrm{TB}$ patients who incur catastrophic costs as a result of the cost of care, and to monitor these metrics over time. Findings from these surveys should also help identify entry points for developing policies to ensure better financial and social protection for TB patients. ${ }^{8}$

As of July 2018, 11 countries had conducted a TB patient cost survey using the WHO instrument and methodology, ${ }^{13}$ four surveys were ongoing or near completion, and 13 countries were planning and mobilising funding to conduct such surveys (Figure).

In the present paper, we describe the key notions that are measured using these TB patient cost surveys, notably the types of costs that are captured, and measures of the affordability of these costs in relation to household income, expressed as occurrence of catastrophic costs and impoverishment. We discuss the standard methods for measuring these concepts and how they have been adapted in the TB patient cost survey handbook, and conclude by highlighting areas for consideration for those implementing TB patient cost surveys.

\section{DEFINING ECONOMIC BURDEN FOR PATIENTS AND HOUSEHOLDS}

At the heart of the UHC paradigm is the concept that families should not face undue financial hardship in accessing health care. This is referred to as financial protection, and it builds on the notion of affordability of care. ${ }^{14,15}$ The WHO and the World Bank track financial protection through two indicators: high (or catastrophic) health spending and impoverishment. ${ }^{6}$ Catastrophic health spending quantifies the proportion of the population whose resources would be catastrophically reduced by spending on health care. ${ }^{16}$ When health care expenditures exceed a given proportion of available income (or expenditure capacity), they are considered 'catastrophic'. The impoverishment approach estimates the proportion of the population that would be pushed below a defined poverty line due to seeking and receiving care. ${ }^{17}$ Catastrophic spending and impoverishment rates are generally calculated using household level data captured through population-based surveys.

\section{MEASURING CATASTROPHIC HEALTH SPENDING}

When measuring catastrophic health spending, there are two key variables underlying this approach: 1) total household out-of-pocket payments for health care (numerator, see the following Sections on 'Measuring and valuing household costs' and 'Generating a ratio of health care costs to a measure of ability to pay'); and 2) a measure of household resources (denominator, see Section on 'Measuring ability to pay'). A ratio of health care costs to a measure of ability to pay can then be generated (see Section on 'Generating a ratio of health care costs to a measure of ability to pay'), which is compared to a threshold (see Section on 'Defining thresholds for catastrophic payments').

\section{Measuring and valuing household costs}

While the UHC indicator uses household surveys to capture health care expenditures (medical costs) for all conditions, the $\mathrm{TB}$ indicator aims to capture instead the total economic burden related to one diagnosed health condition only, i.e., TB. The UHC indicator focuses on direct out-of-pocket medical costs only.

TB patient cost surveys measure three types of cost: direct medical costs, direct non-medical costs and income loss (indirect costs or opportunity costs). Direct medical costs represent the money actually spent out of pocket by the patient on medical services such as prescribed medications, consultation fees, hospitalisation and laboratory tests. These costs are the same as the direct medical costs measured in the UHC framework.

Patients (and their carers) often incur other direct costs associated with the utilisation of health care, such as transport costs to and from the health facility, and costs for accommodation and food, which are referred to as direct non-medical costs. Direct costs are valued by asking patients to recall their actual expenditure.

When seeking care and when sick, individuals also incur costs associated with lost productivity due to illness/disability and time spent seeking care, or looking after a patient instead of working (i.e., carers). These opportunity costs are referred to as indirect costs in the End TB monitoring framework. Two approaches are typically employed to value indirect costs to households: the human capital approach and the output-based approach. ${ }^{18}$

The human capital approach involves valuing an individual's time by multiplying the number of hours spent seeking and receiving care/caring for by their reported or estimated hourly wage rate. ${ }^{19}$ If based on reported income, this method can have equity concerns, as it then implicitly values the time of more productive (higher income) individuals more highly and does not take into account the value of time lost by individuals who are performing unpaid work or are unemployed or retired. ${ }^{20}$ This can be corrected by using a standard estimated income for these individuals (e.g., the mean for the lower quintiles based on national statistics or the minimum civil servant wage).

The output-based approach considers reported changes in income/production. ${ }^{21}$ This approach is recommended by the WHO for settings predomi- 


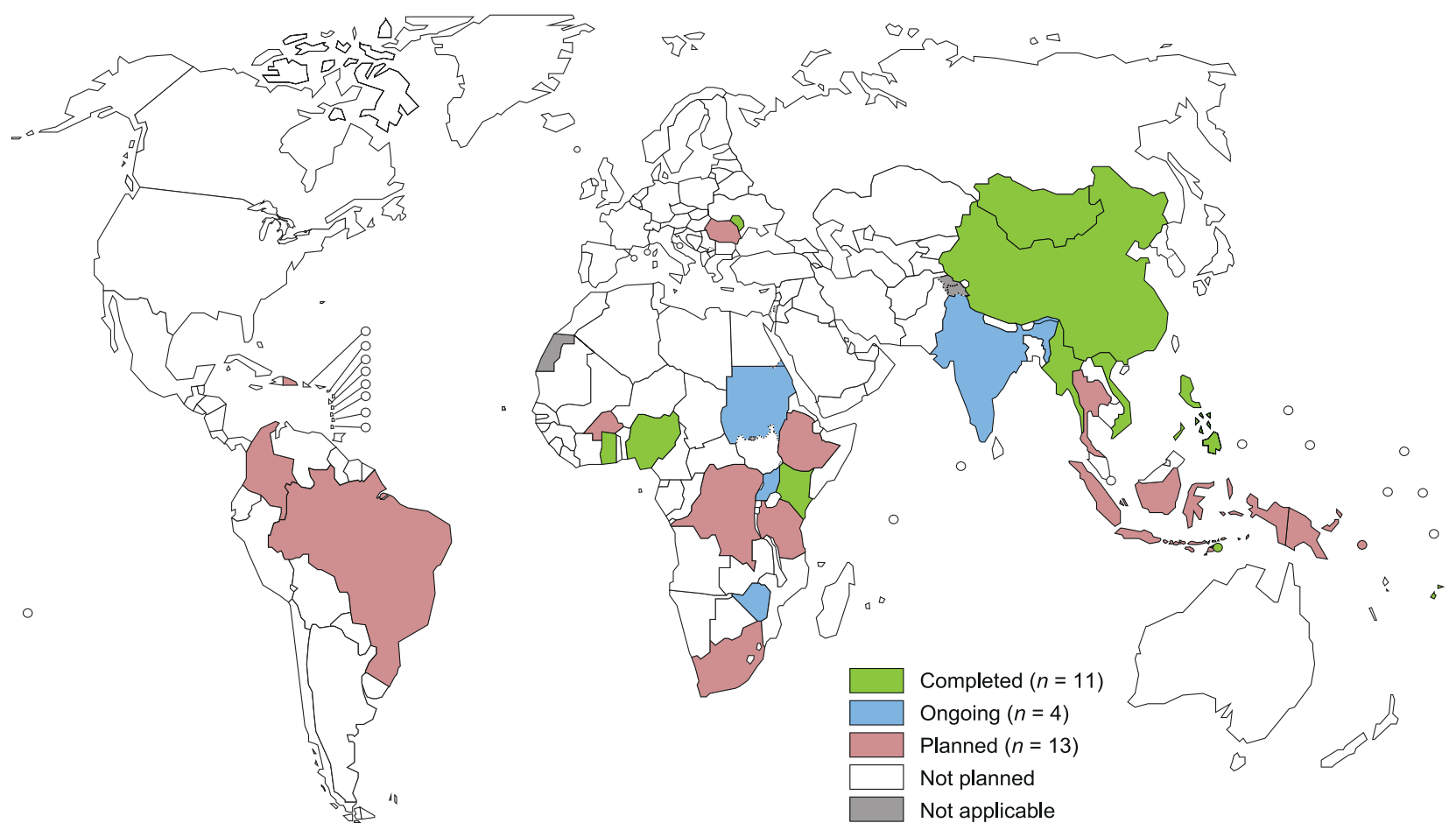

Figure Global implementation of TB patient cost surveys following the WHO methodology as of July 2018. Source: WHO Global TB Programme, July 2018. ${ }^{12} \mathrm{~TB}=$ tuberculosis; $\mathrm{WHO}=$ World Health Organization. This image can be viewed online in colour at http:// www.ingentaconnect.com/content/iuatld/ijtld/2019/00000023/00000001/art000...

nantly characterised by formal economies, where individuals can reliably report income in monetary terms.

The WHO's generic instrument for TB patient cost surveys collects data that allow the valuation of both indirect costs using the human capital approach and the output-based approach (Table 1). ${ }^{13}$ The End TB Strategy indicator is generally computed on the basis of the output-based approach, while the human capital approach is used in sensitivity analyses. The reason for capturing these data in $\mathrm{TB}$ patient cost surveys is to encourage the valuation of TB-related indirect costs, as such evidence is currently limited. ${ }^{13,22-24}$ To date, researchers have generally employed the human capital approach to value productivity losses associated with $\mathrm{TB}$, with varying levels of precision in the estimations of time and income. However, more than a third of studies included in one recent systematic review that presented indirect costs did not clearly explain the methods that were used to calculate them. ${ }^{25}$

The economic burden of illness can be measured at the individual level, but it is perhaps more practical to look at the economic impact on the whole household, particularly as other household members also contribute to direct expenditures and may take time off work to care for the ill person or take their children out of school to contribute to the household income. ${ }^{26}$ The affordability of TB costs is also analysed at the household level due to the impact that TB potentially has on households, as discussed below.

\section{Measuring the ability to pay}

Ability to pay is usually measured in terms of income, consumption or expenditure. Income refers to earnings from employment and sale of assets and receipt of transfers. Consumption refers to spending on resources (goods and services) consumed by the household. Expenditure excludes consumption that is not based on market transactions (e.g., home production), and refers to goods or services that are purchased but not immediately consumed by the household. ${ }^{27}$

While reported income is the gold standard measure of ability to pay, in low-income settings, where employment is mainly outside the formal sector and income is hard to measure reliably, consumption expenditure is often believed to be a more valid measure of economic resources than income. However, both remain difficult and costly to collect. ${ }^{28-31}$

In the UHC framework, consumption expenditure is often used rather than income to measure catastrophic expenditure and impoverishment. ${ }^{6}$ It can be argued that deducting food spending from consumption (non-food expenditure) can better capture a household's ability to pay for health expenditures. ${ }^{6}$ Alternatively, no deduction for necessities is made.

TB patient cost surveys capture either income or 
Table 1 Summary of recommended and additional approaches, metrics and valuation methods for TB patient cost surveys based on the World Health Organization methodology ${ }^{12}$

\begin{tabular}{|c|c|c|}
\hline Approach/valuation method/metric & Recommended & Additional \\
\hline \multicolumn{3}{|l|}{ Costs } \\
\hline \multicolumn{3}{|l|}{ Direct } \\
\hline Cost disaggregation (medical/non-medical) & $x$ & \\
\hline \multicolumn{3}{|l|}{ Indirect } \\
\hline Human capital approach & $x$ & \\
\hline Output-related approach & $x$ & \\
\hline \multirow{2}{*}{\multicolumn{3}{|c|}{$\begin{array}{l}\text { Measure of living standards } \\
\text { Income }\end{array}$}} \\
\hline & & \\
\hline $\begin{array}{l}\text { Reported individual and household income pre- and } \\
\text { post-TB diagnosis }\end{array}$ & $x$ & \\
\hline Asset-based income & $x$ & \\
\hline Consumption expenditure & $x$ & \\
\hline \multicolumn{3}{|l|}{ Measures of financial protection } \\
\hline \multicolumn{3}{|l|}{ Catastrophe } \\
\hline Catastrophic payment headcount & $x$ & \\
\hline \multirow{2}{*}{\multicolumn{3}{|c|}{ Impoverishment }} \\
\hline & & \\
\hline Incidence of impoverishment & & $x$ \\
\hline Depth of poverty & & $x$ \\
\hline \multicolumn{3}{|l|}{ Threshold } \\
\hline \multicolumn{3}{|l|}{ Catastrophe } \\
\hline $20 \%$ threshold & $x$ & \\
\hline $\begin{array}{l}\text { Sensitivity analysis with different proportions of } \\
\text { income threshold }\end{array}$ & $x$ & \\
\hline \multicolumn{3}{|l|}{ Impoverishment } \\
\hline International poverty lines (e.g., USD 1.25/day in 2005 PPPs) & & $x$ \\
\hline National/locally defined relevant poverty lines & & $x$ \\
\hline
\end{tabular}

consumption expenditure, or both. The TB indicator is computed using the measure of income that is more robust in the specific country setting. For countries collecting more than one measure, the more robust will be used for main analysis and the alternative measures in sensitivity analysis.

Generating a ratio of health care costs to a measure of ability to pay

When computing catastrophic spending within the UHC monitoring framework, the numerator is restricted to direct medical costs, ${ }^{32}$ and does not measure direct non-medical and indirect costs, as UHC is mainly about moving towards progressive and equitable health care financing, and national financing schemes (tax or insurance-based) covering direct medical costs.

The End TB monitoring framework, on the other hand, is designed to also collect data that can guide policies on patient-centred service delivery models that can reduce both direct and indirect costs, as well as social protection schemes for income security and social support. A key element of innovation of the End TB Strategy 'zero catastrophic costs' indicator is thus that the numerator comprises direct medical, non-medical and indirect costs. In TB care, indirect costs have been found to account for a sizeable proportion of total costs (on average $60 \%$ of total costs, range $16-94 \%$ ) in $\mathrm{LMICs}^{33}$ these are therefore important elements for capturing all care-related expenditures and the economic impact on $\mathrm{TB}$ patients, from the onset of symptoms to the end of anti-tuberculosis treatment. The denominator is further defined as annual household income or annual household consumption expenditure, as outlined in the section 'Measuring ability to pay'. ${ }^{34}$ The resulting ratio is then compared to the thresholds defined below to determine whether spending is catastrophic.

\section{Defining thresholds for catastrophic payments}

The catastrophic payment threshold is set as a proportion of income, i.e., households should not spend more than a pre-defined proportion of their income on health care. When a household's health care payments exceed that pre-defined threshold, they are defined as catastrophic. ${ }^{16}$ The choice of the threshold has so far been arbitrary. Various thresholds have been used in the literature: $10 \%, 3515 \%$ of household annual income, ${ }^{36}$ or $40 \%$ of household non-food expenditure. ${ }^{32,37}$ The WHO and the World Bank now track catastrophic spending on the basis of out-of-pocket expenditures exceeding $10 \%$ or $25 \%$ of household total income or consumption. ${ }^{6}$

For global monitoring of the End TB Strategy 'zero catastrophic costs' indicator, in 2017, the WHO chose to use a threshold of $20 \%$ of annual household income, ${ }^{13}$ which was set through expert opinion voting in the task force. This is the threshold that is currently used by national TB programmes (NTPs) 
Table 2 Summary of key measures of catastrophic health spending and impoverishment for general Universal Health Coverage monitoring (source: adapted from ${ }^{40}$ )

\begin{tabular}{lc}
\hline Indicator & What it is measuring \\
\hline $\begin{array}{l}\text { Concept of catastrophic health expenditure: key indicators } \\
\text { Catastrophic payment headcount (or incidence of catastrophic } \\
\text { health expenditure) }\end{array}$ & $\begin{array}{c}\text { Proportion of households in a population who face catastrophic } \\
\text { health expenditure } \\
\text { Catastrophic payment gap (or excess or mean positive } \\
\text { catastrophic overshoot) }\end{array}$ \\
$\begin{array}{c}\text { Concept of impoverishment due to health spending: key indicators } \\
\text { Incidence of impoverishment }\end{array}$ & $\begin{array}{c}\text { Proportion of households in a population who fall into poverty due } \\
\text { to health care spending }\end{array}$ \\
$\begin{array}{c}\text { Poverty gap (or increase in the depth of poverty) } \\
\text { Percentage points by which a household falls further into poverty } \\
\text { due to health care spending }\end{array}$ \\
\hline
\end{tabular}

that implement TB patient cost surveys whose results are annually reported to the WHO.,1,38 Countries that conduct national TB patient cost surveys are encouraged to undertake sensitivity analyses whereby the $20 \%$ threshold is altered so that the proportion of patients facing catastrophic costs can be assessed at different thresholds, and potentially inform a review of the threshold in the future (Table 1).

The threshold can be used to help define two measures of catastrophic health spending, in both the UHC and the End TB Strategy framework. The catastrophic payment headcount measures the incidence of catastrophic health care costs (i.e., the number, or proportion, of individuals who have been exposed to catastrophic expenses). The catastrophic payment gap (or excess) measure is used to assess the intensity or severity of catastrophic spending by looking at the extent to which health care costs exceed the pre-defined threshold (Table 1). ${ }^{16}$

The proportion of patients incurring catastrophic costs due to $\mathrm{TB}$ is derived from the number of $\mathrm{TB}$ patients with catastrophic costs divided by the number of all TB patients treated at NTP facilities. This means that the sampling frame is notified patients on treatment, rather than all people with TB in the community or households in a country. This is selected for practical reasons, as the only available sampling frame is notified TB patients, and household surveys would require a large sample size to include a sufficient number of prevalent TB cases.

\section{MEASURING IMPOVERISHMENT}

An additional measure of the affordability of care used for UHC monitoring is impoverishment, or whether health care costs push households into poverty (or more deeply into poverty). In this case, the threshold is absolute and set in terms of a poverty line. If health care payments cause household income/consumption expenditure to fall below the poverty line, they are considered 'impoverishing'. The widely used international dollar-a-day poverty line proposed by the World Bank to allow international comparability was replaced by USD 1.25/day in 2009, at 2005 purchasing power parity. ${ }^{39}$ Countries also have their own national poverty lines which may be relevant for comparing impoverishment over time within a country.

The incidence of impoverishment measures the increase in poverty due to health care spending. The poverty gap is the shortfall from the poverty line. While these are not included in the End TB Strategy monitoring, countries can include them in the analyses of TB patient cost surveys. Table 2 provides a summary of the key measures presented in this section and in the Section, 'Defining thresholds for catastrophic payments'.

\section{TOWARDS ZERO FAMILIES FACING CATASTROPHIC COSTS DUE TO TUBERCULOSIS: AREAS FOR CONSIDERATION}

The End TB Strategy target is a first important step in broadening the concept and measurement of affordability to account not only for medical costs but also for the broader economic impact of $\mathrm{TB}$, including non-medical and indirect costs.

However, as described above, the application of the concepts and standard methods of financial protection requires further development in the End TB Strategy. The WHO recently published a handbook based on the experiences and data from the first round of surveys between 2016 and 2017, which provides comprehensive guidance for conducting facility-based cross-sectional surveys to assess TB patient costs. ${ }^{13}$ This would benefit from periodic methodological updates based on multicountry analyses of survey findings and strengthen collaboration with health economists, NTPs and policy makers. These updates include methods for calculating confidence intervals for key survey indicators adjusted for the sampling design, a regression-based approach for imputing missing costs, recommendations on the design of a household expenditure questionnaire (to derive a household income measure based on expenditure) and adaptation of the survey instrument to high-income settings.

There are a number of areas for consideration for those implementing TB patient cost surveys going 
forward, including descriptive analyses of costs that unpack direct medical and non-medical costs and indirect costs, as they can provide valuable information to identify entry points for appropriate polices and interventions to minimise these costs; the use of both the human capital and the output-based approaches to value indirect costs for comparison and correlation; and measuring and comparing income and consumption expenditure to compute financial protection measures. Approaches and metrics in addition to the standard End TB Strategy framework methodology include measuring impoverishment, computing the catastrophic payment gap and sensitivity analyses with different proportions of income thresholds (Table 1).

Finally, it is important to bear in mind that the cross-sectional study design for a TB patient cost survey recommended by the WHO inevitably focuses on the economic consequences of TB using a measure at one point in time. It therefore fails to capture the long-term economic consequences of the disease for the household, including the impact on reduced labour supply and productivity, and household resilience. Coping mechanisms were originally explored as part of the development of the TB indicator, as they were deemed to be potentially less labour intensive to collect and easier to integrate in routine surveillance. However, as coping mechanisms differ in different cultures and societies, it is difficult to consider them as a proxy for catastrophic payments.

Several research studies that have adapted the WHO generic protocol to a longitudinal design, including for long-term follow-up after anti-tuberculosis treatment, are now ongoing. These studies will be helpful for the validation and interpretation of cross-sectional TB patient cost survey data. Separate studies of non-notified TB patients, such as those in private care, are required to measure costs in situations where user charges for clinical care are often higher than in facilities linked to NTPs. However, other studies sampling people with TB who are not under treatment at the time of the study are also needed, as the current methodology only includes TB patients who remain in care. Such studies can be conducted in the context of tracing patients who are lost to follow-up (e.g., initial loss to followup or loss to follow-up during treatment) by reconnecting them with treatment and explore reasons for loss to follow-up. The assessment of costs incurred by such patients may shed light on costs related to the disease and disability that are not linked to care seeking, and costs of living with $\mathrm{TB}$ without getting proper care.

\section{CONCLUSIONS}

In this paper, we have described economic burden and affordability concepts and measurements that under- lie the End TB Strategy indicator of 'zero catastrophic costs' due to $\mathrm{TB}$, and have highlighted the novel elements of this indicator in relation to approaches used in the UHC monitoring framework. Further findings from national TB patient cost surveys, multicountry analyses and research using alternative approaches will be important in providing further evidence to refine metrics and methodology for country-level implementation and global monitoring.

The conventional concepts and measurement of 'financial protection' of the UHC monitoring framework have been taken a step forward in the End TB Strategy to ensure metrics are able to capture the total economic burden of TB on patients and families. This approach has the potential to inform the design of financing and implementation of both health care and social protection policies that aim to prevent both direct and indirect costs of care, and ultimately ensure that TB care is truly affordable for TB patients.

\section{Acknowledgements}

The authors would like to acknowledge the input and valuable comments from I Garcia Baena, N Nishikiori and A Siroka at the Global Tuberculosis Programme, World Health Organization, and the work of the experts of the Global Task Force on TB Patient Cost Surveys. DP and RH are funded by the United States Agency for International Development (USAID) through TREAT-TB grant GHN-A-00-08-000400. KV is supported by a Sidney Sax Early Career Fellowship from the Australian National Health and Medical Research Council, Canberra ACT, Australia (GNT1121611).

Conflicts of interest: none declared. This is an open access article distributed under the terms of the Creative Commons Attribution License, which permits unrestricted use, distribution, and reproduction in any medium, provided the original author and source are credited.

\section{References}

1 World Health Organization. Global tuberculosis report, 2016. WHO/HTM/TB/2016.13. Geneva, Switzerland: WHO, 2016.

2 Dubos R J, Dubos J. The white plague: tuberculosis, man, and society. New Brunswick, NJ, USA: Rutgers University Press, 1952.

3 McIntyre D, Garshong B, Mtei G, et al. Beyond fragmentation and towards universal coverage: insights from Ghana, South Africa and the United Republic of Tanzania. Bull World Health Organ 2008; 86: 871-876.

4 Ukwaja K N, Alobu I, Lgwenyi C, Hopewell P C. The high cost of free tuberculosis services: patient and household costs associated with tuberculosis care in Ebonyi State, Nigeria. PLOS ONE 2013; 8: e73134.

5 Mauch V, Bonsu F, Gyapong M, Awini E, Suarez P, Marcelino B. Free tuberculosis diagnosis and treatment are not enough: patient cost evidence from three continents. Int J Tuberc Lung Dis 2013; 17: 381-387.

6 World Health Organization. Tracking Universal Health Coverage. Washington, DC, USA: WHO, 2017.

7 Dye C, Floyd K. Tuberculosis. In: Jamison D T, Breman J G, Measham A R, et al., eds. Disease control priorities in developing countries. Chapter 16. 2nd ed. Washington, DC, USA: The International Bank for Reconstruction and Development \& The World Bank, 2006. https:/www.ncbi. nlm.nih.gov/books/NBK11724/ Accessed November 2017. 
8 Tanimura T, Jaramillo E, Weil D, Raviglione M, Lönnroth K. Financial burden for tuberculosis patients in low- and middleincome countries: a systematic review. Eur Respir J 2014; 43: 1763-1775.

9 Lönnroth K, Glaziou P, Weil D, Floyd K, Uplekar M, Raviglione M. Beyond UHC: monitoring health and social protection coverage in the context of tuberculosis care and prevention. PLOS Med 2014; 11: e1001693.

10 Uplekar M, Weil D, Lönnroth K, Jaramillo E, Lienhardt C, Dias H M. WHO's new End TB Strategy. Lancet 2015; 385: 1799-1801.

11 Lönnroth K, Glaziou P, Weil D, Floyd K, Uplekar M, Raviglione M. Beyond UHC: monitoring health and social protection coverage in the context of tuberculosis care and prevention. PLOS Med 2014; 11: e1001693.

12 KNCV Tuberculosis Foundation, World Health Organization, Japan Anti-Tuberculosis Association. The tool to estimate patients' costs. The Hague, The Netherlands: TBCTA, 2008.

13 World Health Organization. Tuberculosis patient cost surveys: a handbook. Geneva, Switzerland: WHO, 2017.

14 McIntyre D I, Thiede M, Birch S. Access as a policy-relevant concept in low- and middle-income countries. Health Econ Policy Law 2009; 4: 179-193.

15 McIntyre D, Thiede M, Dahlgren G, Whitehead M. What are the economic consequences for households of illness and of paying for health care in low- and middle-income country contexts? Soc Sci Med 1982; 2006: 62.

16 Wagstaff A, Doorslaer E. Catastrophe and impoverishment in paying for health care: with applications to Vietnam 19931998. Health Econ 2003; 12: 921-934.

17 Niëns L. Affordability in health care: operationalizations and applications in different contexts [Ph.D. thesis]. Rotterdam, The Netherlands: Erasmus University, 2014.

18 Drummond M F, McGuire A. Economic evaluation in health care: merging theory with practice: Oxford, UK: Oxford University Press, 2001.

19 World Health Organization. Protocol for survey to determine direct and indirect costs due to $\mathrm{TB}$ and to estimate proportion of TB-affected households experiencing catastrophic total costs due to TB. Geneva, Switzerland: WHO, 2015. http://www. who.int/tb/advisory_bodies/impact_measurement_taskforce/ meetings/tf6_background_5a_patient_cost_surveys_protocol. pdf Accessed October 2018.

20 Lensberg B R, Drummond M F, Danchenko N, Despiégel N, François $\mathrm{C}$. Challenges in measuring and valuing productivity costs, and their relevance in mood disorders. Clinicoecon Outcomes Res 2013; 5: 565-573.

21 World Health Organization. WHO guide to identifying the economic consequences of disease and injury. Geneva, Switzerland: WHO, 2009. http://www.who.int/choice/ publications/d_economic_impact_guide.pdf Accessed October 2018.

22 Foster N, Vassall A, Cleary S, Cunnama L, Churchyard G, Sinanovic E. The economic burden of TB diagnosis and treatment in South Africa. Soc Sci Med 2015; 130: 42-50.

23 Mauch V, Woods N, Kirubi B, Kipruto H, Sitienei J, Klinkenberg E. Assessing access barriers to tuberculosis care with the tool to estimate patients' costs: pilot results from two districts in Kenya. BMC Public Health 2011; 11: 43.

24 Sinanovic E, Floyd K, Dudley L, Azevedo V, Grant R, Maher D. Cost and cost-effectiveness of community-based care for tuberculosis in Cape Town, South Africa. Int J Tuberc Lung Dis 2003; 7 (Suppl 1): S56-S62.

25 Laurence Y V, Griffiths U K, Vassall A. Costs to health services and the patient of treating tuberculosis: a systematic literature review. PharmacoEconomics 2015; 33: 939-955.

26 Russell S. The economic burden of illness for households in developing countries: a review of studies focusing on malaria, tuberculosis, and human immunodeficiency virus/acquired immunodeficiency syndrome. Am J Trop Med Hyg 2004; 71 (Suppl): S147-S155.

27 International Labour Organization. Household income and expenditure statistics. Geneva, Switzerland: ILO, 2003.

28 Galobardes B, Shaw M, Lawlor D A, Lynch J W, Davey Smith G. Indicators of socio-economic position (Part 1). J Epidemiol Community Health 2006; 60: 7-12.

29 Howe L D, Galobardes B, Matijasevich A, et al. Measuring socio-economic position for epidemiological studies in low- and middle-income countries: a methods of measurement in epidemiology paper. Int J Epidemiol 2012; 41: 871-886.

30 Galobardes B, Shaw M, Lawlor D A, Lynch J W, Davey Smith G. Indicators of socio-economic position (Part 2). J Epidemiol Community Health 2006; 60: 95-101.

31 O’Donnell O, van Doorslaer E, Wagstaff A, Lindelow M. Analyzing health equity using household survey data. Washington DC, USA: World Bank Institute Development Studies, 2007.

$32 \mathrm{Ke} \mathrm{Xu} \mathrm{K.} \mathrm{Distribution} \mathrm{of} \mathrm{health} \mathrm{payments} \mathrm{and} \mathrm{catastrophic}$ expenditures methodology. Geneva, Switzerland: World Health Organization, 2005.

33 Tanimura T, Jaramillo E, Weil D, Raviglione M, Lönnroth K. Financial burden for tuberculosis patients in low-and middleincome countries: a systematic review. Eur Respir J 2014; 43 : $1763-1775$

34 Ataguba J E, Akazili J, McIntyre D. Socioeconomic-related health inequality in South Africa: evidence from general household surveys. Int J Equity Health 2011; 10: 48.

35 Ranson M K. Reduction of catastrophic health care expenditures by a community-based health insurance scheme in Gujarat, India: current experiences and challenges. Bull World Health Organ 2002; 80: 613-621.

36 Wyszewianski L. Financially catastrophic and high-cost cases: definitions, distinctions, and their implications for policy formulation. Inquiry 1986; 23: 382-394.

37 Kawabata K, Xu K, Carrin G. Preventing impoverishment through protection against catastrophic health expenditure. Bull World Health Organ 2002; 80: 612.

38 World Health Organization. Tuberculosis country profiles. Geneva, Switzerland: WHO, 2017.

39 Ravallion M, Chen S, Sangraula P. Dollar a day revisited. World Bank Econ Rev 2009; 23: 163-184.

40 Saksena P, Hsu J, Evans D B. Financial risk protection and universal health coverage: evidence and measurement challenges. PLOS Med 2014; 11: e1001701. 
La tuberculose (TB) est une maladie de la pauvreté. Assurer l'accès aux soins de santé sans risque de difficultés financières dues aux dépenses de santé (couverture de santé universelle [UHC]) est essentiel pour permettre l'accès aux soins des populations défavorisées, mais cela ne suffit pas. La stratégie Halte à la TB promeut à la fois des services de TB et des mesures de protection sociale centrées sur le patient, qui visent à atténuer les difficultés économiques des patients TB et de leurs foyers dues aux dépenses médicales et non médicales directes ainsi qu'à la perte de revenu. La stratégie inclut l'objectif qu'aucune famille ne soit confrontée à des coûts totaux catastrophique dus à la TB. L'indicateur lié à cet objectif vise à capturer le fardeau économique total lié aux soins de TB, et diffère donc de l'indicateur "dépenses de santé catastrophiques ", un composant clé du cadre de suivi UHC, aligné aux Objectifs de Développement Durable. Les pays, surtout ceux très frappés par la TB, devraient réaliser des enquêtes, représentatives de chaque pays, à propos des coûts pour les patients TB afin d'établir des mesures de base de l'indicateur de coûts catastrophiques. Les résultats de ces enquêtes devraient contribuer à identifier les points de départ d'élaboration des politiques visant à assurer une meilleure protection financière et sociale des patients TB. Dans cet article, nous définissons les concepts clés mesurables par les enquêtes de coût des patients TB, notamment les types de coûts qui sont capturés et les mesures d'accessibilité qui y sont liées. Nous discutons les méthodes de mesure de ces notions dans le cadre conceptuel de l'UHC et le contraste avec la façon dont elles sont mesurées lors des enquêtes de coût pour les patients TB.
La tuberculosis (TB) es una enfermedad de la pobreza. Procurar un acceso a la atención de salud sin el riesgo de dificultades económicas debido a los gastos directos de la atención (cobertura universal de salud [UHC]) es primordial cuando se busca prestar una atención accesible a las poblaciones desfavorecidas, pero no es suficiente. La Estrategia Fin a la Tuberculosis promueve servicios de TB centrados en el paciente y también medidas de protección social, encaminadas a mitigar las dificultades económicas de los pacientes con TB y sus hogares, debidas a los gastos directos médicos y de otro tipo y también a la pérdida de ingresos. Uno de los objetivos de la estrategia consiste en que no haya familias que tengan que hacer frente a gastos catastróficos debido a la TB. El indicador vinculado con este objetivo busca captar la carga económica total que se asocia con la atención de la TB y con ello difiere del indicador de 'los gastos catastróficos de salud', que es un componente primordial del marco de la vigilancia de la UHC, en consonancia con los Objetivos de Desarrollo Sostenible. Se prevé que los países, en especial los que soportan una alta carga de morbilidad por TB, realicen encuestas nacionales representativas sobre los costos que cubren los pacientes, con el fin de fijar las medidas de referencia para el indicador de los gastos catastróficos. Los resultados de estas encuestas deberían contribuir además, a reconocer los puntos de acceso para formular políticas que garanticen una mejor protección económica y social a los pacientes con TB. En el presente artículo se definen conceptos primordiales medibles para las encuestas sobre los costos de los pacientes con TB, en especial los tipos de costos que se han de captar y las medidas conexas de asequibilidad. Se analizan los métodos de medición de estas nociones en el marco de la UHC y se contrastan con la forma como se miden en las encuestas de los costos de los pacientes con TB. 